\title{
Nuevos textos olvidados de Pedro Salinas en su estancia sevillana
}

\author{
José María Barrera López
}

El 27 de noviembre de 1991 se cumple el primer aniversario del nacimiento de Pedro Salinas Serrano, catedrático de Literatura en la Facultad de Letras de Sevilla (1918-1930) y poeta maior del 27. Casi toda su obra completa, tanto poética como narrativa, ensayística o teatral, ha sido recogida por su hija, Soledad Salinas y su yerno, Juan Marichal, a lo largo de los años setenta y ochenta ${ }^{1}$. Sin embargo una interesante labor de rastreo y confrontación de poemas y prosas, en revistas, con los publicados en libros nos ha llevado a «descubrir» nuevos textos nunca antes estudiados.

En Índice «revista de definición y concordia», de Juan Ramón Jiménez, figuran dos textos en prosa que Salinas no recogió en su obras. Son «Dos intermedios de lectura. I. Para el segundo entreacto de La vida es sueño. II. Para un descanso en La recherche du temps perdu, emprendida por M. Proust» (n. 2, 1921) y «Un conocido por conocen» (n. 3, 1921).

El referido a Calderón comienza de la siguiente manera:

" ¡Salve Segismundo, más infeliz que el ave, el pez, el bruto y el cristal del arroyo! ¡Cuántas veces has pasado por la cargada atmósfera de los teatros en las tardes dominicales, haciendo tus aprendidas piruetas entre dos abismos, bárbaro toreador del bien y del mal! iHay que desobedecer a los astros, esclavos del presagio, y tu grandeza está en el desacato a las estrellas, y en la rebelde desobediencia a los

${ }^{1}$ Pedro Salinas: Poesías Completas (ed. Solita Salinas), Seix Barral, Barcelona, 1971 y 1981; P. Salinas: Narrativa Completa, (ed. Solita Salinas), Barral Editores, Barcelona, 1976; P. Salinas: Ensayos completos (ed. Solita Salinas), Taurus, Madrid, 1983, 3 vols; y P. Salinas: Teatro completo, (ed. Juan Marichal) Aguilar, Madrid, 1957. Cuando se redactan estas líneas están a la espera de publicación las Obras Completas de Pedro Salinas, en la Ed. Aguilar, cuyo plan es el siguiente: T. I y II POESÍA, a cargo de John Crispín; T. III NARRATIVA Y TEATRO COMPLETO, a cargo de Joaquín González Muela y Francisco Ruiz Ramón; T. IV y V ENSAYOS COMPLETOS, a cargo de Jaime Siles y T. VI EPISTOLARIO a cargo de Enric Bou y Andrés Soria. 
humanos. Cuando entras en las cámaras de la corte, con los ojos cargados de sueño, de recuerdo y de ambición, cruzas por las salas donde está sentado el público, la emoción de la gran escena. Tu eres la Justicia, la libertad del albedrio, el humano libertador de ti mismo; tu estudioso padre Basilio, el servil esclavo de la fatalidad y de los injusto».

En su ensayo La realidad y el poeta (1940), Salinas tituló el capítulo, dedicado a Jorge Manrique y Calderón, «La aceptación de la realidad», en contra de la «reproducción» (Poema de Mio Cid), la «idealización» (Garcilaso), la «evasión» (S. Juan, Fray Luis), la «exaltación» (Góngora) o la «rebelión» frente a ésta (Espronceda). El canto de alabanza, a modo de «estampa» impresionista de Índice, tendrá una consecución en la paráfrasis del argumento y en el comentario simbólico y significativo sobre el dramaturgo en el texto inglés de 1940: «Por boca de Segismundo habla el hombre maltratado de todos los tiempos, todo los hombres a quienes se les ha dado vida sin libertad, todos los que han sido encadenados por la sociedad. En Segismundo hablan las víctimas de la injusticia»².

Salinas, en la prosa de la revista, glosa la figura de Segismundo en contraposición a su padre Basilio:

«El campo y la corte se ven frente a frente, y los corazones están latiendo detrás de Segismundo, apelotonada multitud tras de su verbo. Él habla: habla con Clotaldo, que es la lealtad a su señor, la noble y encanecida experiencia con su daga; habla con el criado que es la baja y asalariada experiencia, la prudente voz del escarmentado a palos, y la echa por el balcón, a ese mar que no existió nunca, y según los eruditos es un error de geografía calderoniana, al mar de la justicia inexorable Ya saca la espada contra Astolfo, embajador de los buenos modos, sutil defensor de distinciones entre caballeros cubiertos y descubiertos, hombres grandes y de buena talla. ¿Qué dejas para tu padre, Segismundo, ya empleados - a cada cual lo suyo- espada para el príncipe, daga para el fiel cortesano, puños para el advertido lacayo? Segismundo deja para su padre un arma acariciada años y años en la soledad del monte fragoso, destinada a un corazón desconocido - ¿a cuál sería, Señor?- al corazón del que le colocó por bajo del pez, del bruto y del cristal: es el arma que no inventó el hombre, el arma del niño y del pordiosero, la piedra pesada, dura, terrena, de la buena y justa razón. ;Bien perdidas las cuentas a tu padre!».

También en La realidad y el poeta, nuestro catedrático ve en la «buena y justa razón» la génesis del conflicto de Segismundo. La visión de la realidad para el héroe calderoniano paso por diversas fases. La primera es descorazonadora: la realidad es una condena «una cárcel, como aquella en que vive, si se le compara a la existencia de los único seres vivos que él conoce: animales ${ }^{3}$; la segunda es el pecado «con que ha nacido el hombre, el poder avasallador de los instintos» ${ }^{4}$. Ambas se superarán al tomar con-

\footnotetext{
${ }^{2}$ P. Salinas: La Realidad y el Poeta (1937-1939) en Ensayos Completos, Taurus, Aguilar, 1984, t, I., pág. 219.

${ }^{3}$ Ibidem.

${ }^{4}$ Ibídem, pág. 220.
} 
ciencia de que vivir, obrar, actuar, amar, sufrir son efímeros: «El análisis de la realidad no le trae ninguna certidumbre sobre su propia existencia, ni sobre la realidad de la realidad misma. De ahora en adelante, la sospecha de que todo no sea más que un sueño se cernirá sobre su alma. Por eso no le impedirá seguir adelante. Hay que atreverse a todo valientemente. Hay que vivir. Hay que vivir en la actividad, en actos, en buenas acciones. Porque el hombre sólo puede estar seguro de la capacidad de obrar bien, de su dominio sobre sus propios actos, aunque esos actos tenga lugar en el vacío de un sueño» ${ }^{5}$.

Pero el momento más importante de la obra -recuerda Salinas en Índice- será el final del segundo acto:

«Segismundo... Cuando ya te volvieron a la torre, cuando vida y sueño eran no más que indiferentes vestiduras que tú te pusieras alternativamente y que ahora yacían despreciadas ambas por el suelo, sin apetencia en ti de endosarte ninguna de las dos, porque te bastaba con tu desnudez, sólo en una verdad creías; en la verdad no de una mujer que cruzó por el palacio, ni de una que se asomó a la cueva en su pasado crepúsculo. estrella o Rosaura, no en su corpórea apariencia ni en su capacidad para serfuente de ventura, no, sino el sentimiento de amar, que es lo único que no se acaba, asílo aprendiste en la corte, y el sentimiento de sufrir, que es lo único que no se acaba, que asíte lo enseñaron las montañas. iAdiós Segismundo! Ya no te volveremos a ver. Te perdemos en ese momento supremo en que te quedas afirmando la realidad única del amor y del dolor, sin poner reparo ni atención en las pomposas vestiduras de la vida y el sueño.

«Porque luego, en el otro acto, dicen que sales, pueril intento de engañar nuestra honrada credulidad. No eres tú el que sacan los soldados, el que piden perdón de su violencias, el que se viste a ratos un traje de vivir y otro de soñar, sin saber cuál de los dos es el que vale. Tu drama se acabó al final de la jornada segunda, allí en la cárcel. Y los que te amamos Segismundo y llegamos a penetrar tu virtud, nunca seremos visto por los caminos que llevan al palacio regio, sino por las ásperas tronchas que desenredan su maraña en la soledad salvaje donde está construido tu cárcel».

La solución de Segismundo se esboza, para el escritor madrileño, al final del segundo acto, en su último monólogo. «¿Y es éste el momento más dramático de la obra?» se pregunta en su libro de 1940. Casi veinte años antes, Salinas ya había desentrañado la clave.

La segunda prosa, fruto de la traducción de Le recherche du temps perdu, es un magnífico «retrato psicológico» de Proust:

«el caballero Proust se entrega a su placer favorito: el caballero Proust, artista de fama mundial, recorre el mundo con su Stradivarius de las pasiones, y ha inventado un ejercicio nuevo, El caballero Proust es el virtuoso de la psicología».

${ }^{5}$ Ibídem, pág. 223. 
En 1921 Pedro Salinas ultima su traducción de los dos primeros volúmenes de la novela de Proust (Por el camino de Swuan y A la sombra de las muchachas en flor) que aparecerá en Madrid, en 1922, bajo el título de ésta última. De dicho trabajo, reseña el periódico El Noticiero sevillano: «Todo Proust es una escuela que en él nace, domina y muere. Sus cualidades, tan impersonales como lo son en España las de Ramón Gómez de la Serna, al desbordarse de él, quizá se conviertan en defectos, creando un género tedioso, soporífero, inaguantable, con lo que Proust es sólo una dulce somnolencia evocadora, semejante al borboteo de una fontana bajo una penumbra de rígidos cipreses meditativos ${ }^{6}$.

Ahora, en el texto de Índice, ofrece la metáfora Obra Literaria-Teatro y hace aparecer en escena el «caballero del frac» -Autor- Proust que orquesta -con su lista y su violín- la aparición de sus personajes y sus paisajes: Francisca, tía Leoncia, Odette de Crécy, Swann, Combray. . . :

«Apenas está compuesto un cuadro, cada actor en su sitio, todos apresados en la red de la inmovilidad, el caballero saca de una negra caja un violín, cuyas cuerdas no son las usuales; las de este violín son las que llaman los novelistas delicadas fibras del corazón humano. Y situándose a un lado del escenario, el caballero, con sobrio gesto, comienza a sacar del violín extraños sonidos familiares e inauditos, y de esa caja de madera salen los días de la vida pasada cada cual con su son intimo y peculiar».

Aunque tímidamente iniciada en Seguro azar («Orilla») y Fábula y signo («Mar distante»), la influencia más directa de Marcel Proust en Salinas, se encuentra en sus poemarios La Voz a ti debida y Razón de amor, como bien ha demostrado Bernardo Gicovate: «en estos libros la realidad del amor se convierte para Salinas en sólo la posibilidad de un recordar futuro, y el valor del presente se halla sólo en función de su posibilidad de convertirse en recuerdo en el futuro y de existir entonces como parte del pensamiento. Y llega casi Salinas a repetir en verso una idea esencial de Proust: «La réalité ne se forme que dans la mémorie, les fleurs qu'on me montre aujourd'hui pour la première fois ne me semblent pas de vrais fleurs»?

Nueve años después, en colaboración con José María Quiroga, la ed. Espasa Calpe, publicará su traducción del tercer volumen, El mundo de Guermantes.

La última prosa de Índice es «Un conocido por conocen», pequeño relato que nos anticipa el mundo de Vísperas del gozo (1926). El procedimiento que utiliza su autor es contrario al tradicional, según reseñó Azorín: «El procedimiento recto desaparece. Todo en éles indirecto, fragmentario, inconexo (inconexo aparentemente)» ${ }^{8}$. Bajola anécdota del recuerdo de una cara amiga -joven desconocido-, nuestro poeta del 27 -en su búsqueda introspectiva- refleja el anhelo de posesión de la belleza:

${ }^{6}$ Anónimo: «Traducciones de Pedro Salinas», El Noticiario Sevillano, 19 septiembre 1924.

${ }^{7}$ Bemardo Gicovate: «Pedro Salinas y Marcel Proust: seducción y retomo» en Ensayos sobre Poesía Hispánica. Del Modernismo a la Vanguardia, México, Andrea, 1967, pág. 111.

${ }^{8}$ José Martínez Ruin, Azorín: «El arte de Pedro Salinas», ABC, Madrid, 9 julio 1926. 
«El muchacho estudia un libro de economía. Y en los diez minutos que me quedé a su lado, ni uno solo apartó la vista de su lección. ;Maravilloso dominio de disciplina, señorío perfecto de los sentidos que desdeñan la riqueza sensual que abandonadamente se les ofrece y dejan que la inteligencia reine, única señora, sobre la entera actividad corporal! ¿es que viste el paisaje tanto que esa ya dentro de tí y no necesitas abrir a él los ojos? ¿Es que jamás se te puso delante? No lo sé; lo que si he sabido es que mi rostro desconocido tampoco era el tuyo, doncel lusitano, que tengo que volverme derrotado, con mi careta vacía. Por un rato descanso; me quedo con ella al lado, se me adormece el afán de averiguar su realidad del mundo, y me entretengo en estudiar bien sus facciones, en dejar que me hablen con su apagada y clara expresión los ojos azules e inteligentes, la tez sonrosada y, sobre todo, una sonrisa de hombre delicado que acaso oculta un ánimo exquisito».

$\mathrm{El}$ «conocido» por conocer será el símbolo hombre, que es irrepetible y modelo señero y cierto frente a la multitud. El texto ofrece algunas claves autobiográficas -años de juventud- del escritor:

«Pero otra vez el demonio de las semejanzas me tienta, y allá volvemos a nuestra caminata: a los días de infancia (porque en esos días reinó siempre una niebla tan persistente y sutil que tras ella puede muy bien ocultarse, para ir saliendo oportunamente en años venideros, una legión de rostros vagos y desconocidos, como esos que hay en los fondos rembrantianos), a los años de Universidad (éramos muchos, todos no conocíamos unos a otros, pero cabalmente por eso, nuestro curso llegó a adquirir una expresión única, colectiva, un rostro de todos, y acaso esa cara de hoy era la del compañero, que se sentó día por día, durante años, a mi lado), a las tardes festivales, de grandes muchedumbres, carrera de caballos, partido de football, revista militar (porque entonces, para no ahogarnos en ese vasto mar de cabezas humanas que ondula con tarda pereza, es menester asirse a un color, a un gesto, a un rostro, que nos sirva de punto de apoyo, y de confianza de que no se nos va a escapar el hombre, la cosa señera y cierta entre la turbia multitud); pero todo en vano».

La tercera entrega olvidada de Pedro Salinas, en su período sevillano, se publicó en el semanario España, en el n. 412, 1924, dentro de una serie que el autor tituló «Poesías» en 7 textos y dibujo de Benjamín Palencia. Los poemas están fechados en su final «enero-febrero, 1924» y son los últimos registrados en la revista de Araquistain y Azaña, inmediatamente después de la salida de Presagios.

Recordemos que, aunque el primer libro de Salinas, n. 7 de la colección ÍNDICE (Biblioteca de Definición y Concordia), tiene, en su entrada, la fecha de 1923, por el colofón sabemos que se acabó de imprimir el 30 de enero de 1924. Hasta junio de ese año no se reseña en prensa.

Las entregas I «Con el cielo gris», II «Para cristal te quiero», III «Yo silencioso. Pero», V «Con tu palabra última», VI «iAy, Sevilla, Sevilla,» y VII «Sin armas. Ni las 
dulces» pasaron a su segundo volumen Seguro azar (1929) ${ }^{9}$, quedando sin recoger el Poema IV:
Muchas letras en el libro, muchas palabras de letras, su aguijón cada palabra y cada herida su pena. Cuando la niña venía le daba al libro una vuelta, y así, puestas del revés, iqué claras que se leían cosas alegres, sin letras!

El poema tiene evidentemente una «anécdota» autobiográfica. Esa niña que aparece en él es su hija Solita Salinas, en aquellos momentos con 4 años de edad (nació en Sevilla el 18 de enero de 1920), y, sin duda, ahondando en la anécdota, refleja el tormentoso y asombroso proceso de aprendizaje de la lectura y escritura en el niño. La circunstancia se trasciende con la visión saliniana de la doble «realidad» y del prodigio del mundo -nueva creación (el libro puesto al revés). Si se identifica «palabra» a «dolor» (aguijón, herida) (visión adulta), en un primer momento, la mirada de la niña producirá el cambio: alegría, claridad (visión ingenua de la realidad). El poema ahora cobra toda la dimensión estética: toda lectura (Literatura, letras) es dolorosa (la física y la espiritual, diríamos) para la visión adulta; sin embargo par un niño (tópico tambien literario, es la mirada inocente de la «letra» literaria, todo es distinto: es prodigio, anticipación en el descubrimiento, gozo presentido desinteresado y libre.

Por último, hay que sumar a las anteriores colaboraciones de Salinas una pequeña prosa poética,publicada en primera instancia en La GacetaLiteraria, la revista de Giménez Caballero. El texto lleva fecha de 12 de marzo 1930 y se incluyó en el n. 78 (15 de marzo 1930) de la citada publicación ${ }^{10}$. Comparte página con «4 Sermones» de Rafael Alberti, "Contra éstos y aquéllos, Dios, Patria y Ley» de José Bergamín y «Homenaje» de Benjamín Jarnés. Todos significativamente van dedicados a D. Miguel de Unamuno. Recordemos que en febrero de ese año el rector de Salamanca regresa triunfalmente, sumándose a las voces que piden la inmediata abdicación de Alfonso XIII.

\footnotetext{
9 «Con el cielo gris» esel Poema ACUARELA n. 32 de Seguro Azar; «Para el cristal te quiero» es AMIGA, n. 48; «Yo silencioso. Pero» es INMINENCIA, n. 30; «Con tu palabra última» es DOMINIO, n. 16; «iAy, Sevilla, Sevilla» es SUR, CON VIENTO, n. 35; y «Sin armas. Ni las dulces» es SIN VOZ, DESNUDA, n. 7.

${ }^{10}$ Salinas cesó en su cátedra de Literatura en Sevilla el día 6 de octubre de 1930 al habérsele concedido la permuta solicitada con el catedrático de la Universidad de Murcia Jorge Guillén, aunque desde junio de 1927 fija residencia definitiva en Madrid. Estos datos pueden corroborarse en mi ensayo, Pedro Salinas en la Universidad Literaria de Sevilla. Sevilla, Servicio de Publicaciones de la Universidad de Sevilla 1991. También en mi libro Pedro Salinas. Vida y obra, en prensa.
} 
El texto de Salinas, verdadero retrato de Unamuno, es el siguiente:

\section{ESCALAS}

BULLA. Mete mucha bulla. Escandaliza. Bullidor, inquieto, que desazona, que agita. Peligroso. Un agitador peligroso. Porque bulle.

BULLIR. Agitarse. Bullir la sangre, le bulle la sangre. No bulle, no rebulle, está muerto, inánime. Pero si bulle es que está vivo, que vive. Bullir, vivir agitadamente, como bulle el agua, como hierve el agua, porque bullir es hervir.

HERVIR. Entrar en ebullición, ponerse en bulla. Moverse inquietamente. ¿Para qué? Para ser otra cosa, para cambiar de estado, camino del vapor, de la nube. Ascensión. Trasmutación. Hervir, con h. Pero la h no hierve. Es lo único que no hierve en hervir. Está muerta, es un cuerpo, un resto sin alma. El alma era suf.

F. Letra de la fe. ¿En qué? En todo, fe porfe, fe en la fe, fe por razón de ser fe de vida. Hervido,pero con la letra de la fe, con $f$.

FERVIDO. Ardiente, consumido en ardor, lo que se quema, la llama con conciencia. La conciencia toda llameante, en llamas. Férvido.

Es decir, hirviente, que hierve, que bulle, con la letra de la fe, en hervor, pero con $f e$.

\section{FERVOR.}

Salinas acometió el estudio de distintos aspectos de la obra de Unamuno en diversas ocasiones. En Índice Literario publicó «Unamuno autor dramático» (II, 1 enero 1933), «Las novelas cortas de Unamuno» (II, 7 de agosto 1933) y «Don Juan Tenorio frente a Miguel de Unamuno» (III, 9 noviembre 1934), todos ellos recogidos en Literatura Española Siglo XX (México, Séneca, 1941). Meses antes de morir, el 27 de septiembre de 1951, el suplemento dominical de El Nacional (Caracas), le publicó «El palimsesto poético de Unamuno», recogido póstumamente por Juan Marichal en Ensayos de Literatura Hispánica (1958). Todos ellos demuestran el interés de nuestro catedrático de Literatura por explicar el mundo narrativo, teatral y poético del filósofo vasco.

La prosa de La Gaceta. . . es una «imagen primera» muy particular del escritor. No es un estudio prosopopéyico, un un canto de alabanza ni el tradicional «retrato» de autor. Tampoco es una caracterización literaria al uso. Es una prosa de «definición», juego linguístico creador: la F de FE, de FERVOR, de lucha agónica es esa «letra de abecedario» que define y concretiza al escritor Unamuno.

En «El palimsesto poético. .. ., Salinas lo define como «Amante supremo del verbo»: «Unamuno, distingue, dentro de él, graduación de valores y excelencias: en lo sumo de la escala está la palabra capaz de ritmo, la palabra poetizada y poetizante, la del poeta (. . .). Toda su fe, toda su esperanza cargen sobre sus creaciones».

Esa «valoración» de la escala lingüística-personal (Desde bullidor-agitador social, religioso, político, etc. hasta el fervor-hervor de hombre apasionado por la fe, por la conciencia) es lo que resalta Salinas. 